\title{
Factors affecting the competitiveness of the Australian rail sector: a systems approach to improving service quality
}

\author{
Hadi Ghaderi* \\ Department of Maritime and Logistics Management, \\ National Centre for Ports and Shipping, \\ Australian Maritime College, \\ University of Tasmania, \\ Launceston, Tasmania \\ Email: hghaderi@amc.edu.au \\ and \\ Department of Business Technology and Entrepreneurship, \\ Swinburne Business School, Faculty of Business and Law, \\ Swinburne University of Technology, \\ Hawthorn, Victoria, Australia
}

\section{Stephen Cahoon and Hong-Oanh Nguyen}

Department of Maritime and Logistics Management,

National Centre for Ports and Shipping,

Australian Maritime College,

Launceston, Tasmania, Australia

Email: stephen.cahoon@utas.edu.au

Email: o.nguyen@utas.edu.au

*Corresponding author

\begin{abstract}
The productivity of rail freight transport in Australia is hampered by various impediments. These include infrastructure constraints, commercial barriers, and inconsistent standards and policy, all of which influence the quality attributes of the rail freight service in different ways. Therefore, in order to develop strategies to make rail an attractive mode of transport, it is critical to identify these impediments and assess their relevant influence on the quality of rail service. By adopting a systems approach to competitiveness, this research aims to empirically examine the impact of impediments faced by the rail sector. This approach is beneficial as it: 1) identifies the distinct impact of each impediment on the different freight service attributes (FSA);2) provides important insights to improve the rail service quality; 3) aims to assist government and industry to develop informed transportation and infrastructure planning decision making by identifying the poorer performing areas of system. The analysis identified the key factors influencing the quality of different FSAs relating to: 1) infrastructure management; 2) interoperability; 3) organisational and commercial relationships. The implications derived from this study indicate that the freight rate is still a key area for rail to achieve competitive advantage considering the market characteristics.
\end{abstract}

Keywords: rail freight; intermodal; competitiveness; freight logistics; rail stakeholders. 
Reference to this paper should be made as follows: Ghaderi, H., Cahoon, S. and Nguyen, H.O. (2017) 'Factors affecting the competitiveness of the Australian rail sector: a systems approach to improving service quality', Int. J. Logistics Systems and Management, Vol. 26, No. 3, pp.294-315.

Biographical notes: Hadi Ghaderi was involved as an industrial consultant in private sector before continuing graduate studies. He graduated with Bachelor of Engineering in Industrial System Engineering from Shiraz Azad University, Iran. He obtained his Master of Engineering in Engineering Management from University Putra Malaysia and an Advanced Master of Science in Transport and Maritime Economics from the Institute of Transport and Maritime Management Antwerp (ITMMA), University of Antwerp. He joined the National Centre for Ports and Shipping at Australian Maritime College (UTAS) in 2012 as a PhD student and sessional lecturer. In 2016, he obtained his PhD in Logistics and Supply Chain management. He is now a Lecturer at the Department of Business Technology and Entrepreneurship, Swinburne Business School in Melbourne, Australia. His research interest is in the areas of transport integration, supply chain collaboration and rail freight logistics. He is also a CILTA, SCLAA and ANZAM member.

Stephen Cahoon is the Director of NICTA Logistics Lab in the University of Tasmania. In terms of academic appointments, he is a Council Member of the International Association of Maritime Economists, an Associate Editor of the Asian Journal of Shipping and Logistics and joint guest editor of a special edition of the Growth and Change: Journal of Urban and Regional Policy. He is also active within the maritime and logistics industry in his roles as the Tasmanian Chair of the Chartered Institute of Logistics and Transport of Australia (CILTA), member of the CILTA National Professional Development Committee and CILTA National Council, and member of the Tasmanian Transport and Logistics Workforce Advisory Group.

Hong-Oanh Nguyen is a Senior Lecturer at the Department of maritime and Logistics Management in the University of Tasmania. His research interest is focused on maritime and logistics network analysis; port development, performance valuation and bench marking; investment theory.

\section{Introduction and the rationale for this research}

Freight is an essential element of the Australian economy and a critical sector for the future growth of the nation. Therefore, a robust freight transport system that is sustainable, efficient and safe is necessary to maintain Australia's international competitiveness. Total freight volumes have quadrupled over the past decades (BITRE, 2014a) largely due to:

1 significant growth in mining activity

2 increased domestic and international trade

3 an increasing population (Ghaderi et al., 2015a).

In 2011-12, total domestic freight activity was almost 600 billion kilometres which is equivalent to 26,000 ton kilometers ${ }^{1}$ (tkm) of freight carried for every person in Australia 
(BITRE, 2014b). This continuing growth has however posed complex challenges to government and industry in their planning and infrastructure decision making.

Australian freight activity can be generally categorised into two: bulk and non-bulk. Australia's bulk freight market is dominated by rail transport due to its inherent cost effectiveness and economies of scale, of which an exemplar is the rail transport of coal and iron ore from mines in Western Australia and Queensland to their nearest ports for export. Rail is also involved in transporting smaller quantities of minerals and grains to ports. A benefit of the growth in mining activities has been the access to capital for the development of rail infrastructure, and accordingly greater rail freight activity (BITRE, 2012).

However, the circumstances are comparatively different in the non-bulk ${ }^{2}$ freight sector. The non-bulk freight sector comprises a complex system of consumers, retailers, distributors, transport operators, logistics facilities, suppliers and demand all of which have a significant impact on the wider community in Australia (Wijeweera et al., 2014). Where the movements of goods in the bulk markets typically take place in regional areas, the non-bulk freight activity is tied with the daily life of society (Santos et al., 2015). Non-bulk freight is generally recognised as containerised or other unitised freight, including trailers and imported vehicles. This freight segment demonstrates more diversity and complexity than bulk freight in terms of packaging, distribution networks and the delivery requirements (BITRE, 2009). The total value of the non-bulk supply chains equated to around $2 \%$ of Australia's gross domestic product (GDP) in $2008^{3}$, of which the interstate corridors comprised $61 \%$, port-based systems $34 \%$, and the intrastate chains $5 \%$ (Booz \& Co, 2008). Interstate freight corridors are the primary market segment in Australia where the competition between road and rail is most evident.

In the non-bulk freight sector, modal shares on various routes reflect the relative competitiveness of the different transport modes (Reis, 2014). However, poor service quality is regarded as the major reason for the lower use of rail in the domestic market (ARTC, 2015). On the north-south rail corridor (Brisbane-Sydney-Melbourne) where the major non-bulk freight volumes travel, the on-time reliability until recently has been declining from 2011 , varying between 20 to $80 \%$ compared with road's 95 to $98 \%$. The situation is comparatively more stable in the east-west corridor where rail's reliability has remained between 40 to $80 \%$ (BITRE, 2014c). This is mainly because transporting goods by rail is dependent on other elements of intermodal system, including connecting transport modes and logistics centres such as intermodal terminals. Figure 1 demonstrated the railway network used for the Australian non-bulk movements.

As the result of poor service quality, rail's share in the non-bulk market has remained around $17 \%$ over the past two decades (BITRE, 2014a). Figure 2 demonstrates the comparative task (in billion tkm) of road and rail in the non-bulk freight market from 1995 to 2014. It should be noted that a small volume of non-bulk freight is carried by sea, mainly between Melbourne and Tasmania where there is no land-based connectivity.

According to Ghaderi et al. (2015b) the productivity and competitiveness of rail transport in Australia is hampered by various impediments. These include infrastructure constraints, commercial barriers, and inconsistent standards and policy, all of which influence the quality attributes of the rail freight service in different ways. Therefore, in order to develop strategies to make rail an attractive mode of transport in the non-bulk freight market, it is critical to identify these impediments and assess their relevant influence on the quality of rail service. 
Figure 1 Network used for non-bulk rail freight (see online version for colours)

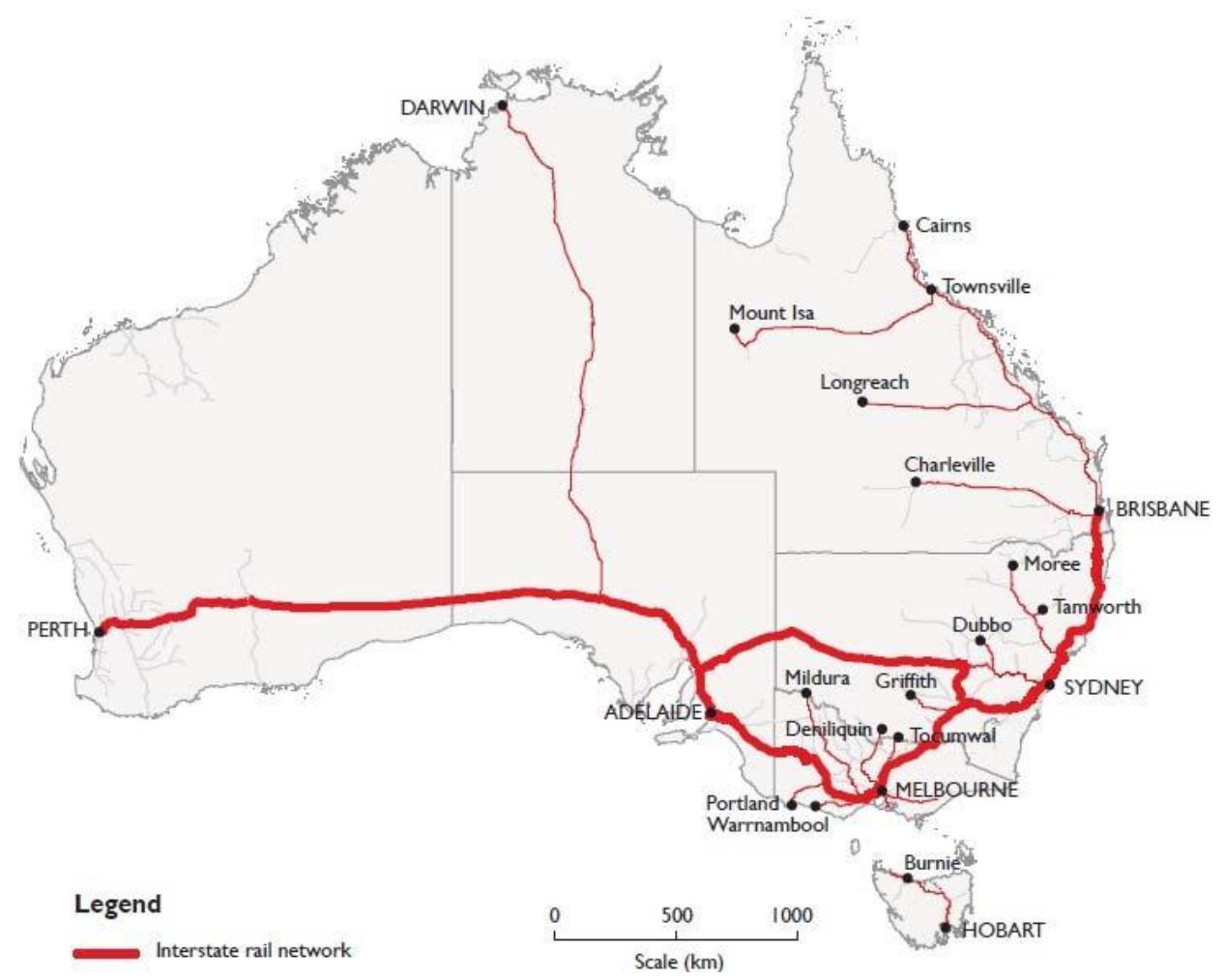

Source: Bitre (2012, p.4)

Figure 2 Comparative share of road and rail from 1995 to 2014

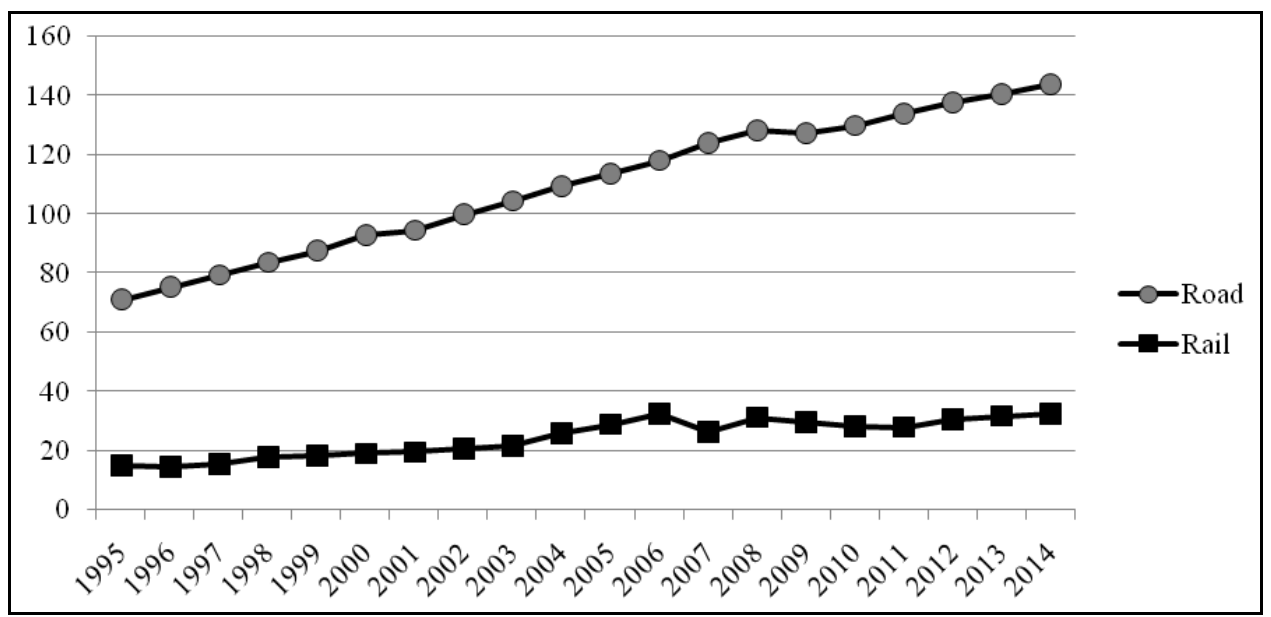

Source: BITRE (2014a) 
This research therefore, aims to empirically examine the impact of impediments faced by the rail sector in Australia on the key freight service attributes (FSA). To meet this objective, an in-depth survey was developed to evaluate the knowledge of rail stakeholders on the key challenges and their applicability on the quality of rail freight service. Accordingly, descriptive and inferential statistical analyses were conducted to explore the view of stakeholders on the identified factors. This approach is beneficial as it:

1 identifies the distinct impact of each impediment on the different FSAs

2 provides important insights to improve the rail service quality

3 aims to assist government and industry to develop informed transportation and infrastructure planning decision making by identifying the poorer performing areas of the system.

The organisation of this paper is as follows: Section 2 presents a brief literature review on the subject of freight mode choice within both the international and Australian context, followed by Section 3 that explains the importance of a systematic study of the rail sector and the underlying theoretical framework of this research. The purpose of Section 4 is to detail the methodological approach for the paper, including the data collection, while the analysis and subsequent discussions are presented in Sections 5 and 6 respectively. In the final section, conclusions are presented and recommendations are provided for improving the quality of the Australia rail freight services.

\section{Factors influencing the customer's choice of freight transport mode}

Over the past three decades there has been increasing attention on the area of freight mode choice and the identification of the key factors influencing the choice of transport mode (Shinghal and Fowkes, 2002; Lu, 2003; Danielis et al., 2005; Meixell and Norbis, 2008; Yang et al., 2014). Many researchers believe that having a clear understanding of these factors is essential for the development of competitive services in freight transport markets (Saranen and Hilmola, 2007; Yu et al., 2013).

The demand for freight service is value-driven. In this sense, the customer's choice of transport service involves a complex trade-off between various key monetary and non-monetary factors such as freight rate (FR), transit time (TT), reliability and service availability (SA) (Begantino et al., 2013; Arencibia et al., 2015). Therefore, the determining factor for a modal shift is whether and to what extent the different modes are able to adapt to the changing requirements of the transport industry (OECD, 2010). Woxenius and Bärthel (2008) argue that the choice of transport solutions for freight is more multifaceted compared to passenger systems as it involves a greater number of actors (for example trucks, rail transport, intermodal terminals and storage facilities), with different values, perceptions and goals.

Flodén et al. (2010) argue that understanding the factors behind the choice of freight transport mode is vital for various reasons. First, from a society perspective, the information can be used for infrastructure planning and investments. Secondly, from a service provider perspective, the information can be used to develop marketing and transport management solutions that consequently enhance the competitiveness of the particular transport mode (Edwards et al., 2001). 
Historically, transportation mode choice was a simple process where the door-to-door freight cost was the dominating decision making factor. Nowadays, mode choice and carrier selection are becoming part of the complex decision making process in transportation management that includes identifying relevant transportation performance variables, selecting the mode of transport and carrier, negotiating rates and service levels, and evaluating carrier performance (Murphy and Poist, 2000; Monczka et al., 2008). Accordingly, there has been an increasing amount of research dedicated to development of methodologies to understand the complexity of transportation mode choice (Mehbub Anwar et al., 2014).

According to Flodén et al. (2010) and Grosso (2011), two main typologies of influential factors on a customer's choice of transport mode can be identified: cost variables and time-based variables. For a door-to-door service the cost factor is determined by the total FR, where the time-based attributes are reflected as:

1 transit-time

2 reliability (punctuality)

3 SA.

Although some other factors can be identified from the literature, they can be indirectly categorised under the key factors mentioned above. For example, damage and loss are normally categorised under FR. In addition to these key factors, the environmental impact of freight services has recently received attention in the area of freight mode choice (Witlox and Vandaele, 2005). However, tools such as carbon tax pricing are instrumental to internalise the associated environmental costs into the FR factor (Fahimnia et al., 2013; Meng et al., 2013).

Historically, the FR was the most important factor influencing the choice of transport mode (Morash and Ozment, 1996). Over the past three decades, the adoption of lean production and just-in-time principles in manufacturing (Fowkes et al., 2004; Kuo and Miller-Hooks, 2012) has resulted in smaller volume flows of freight being delivered at more frequent intervals, thus reducing the transport efficiency of companies supplying these customers (Woodburn, 2003). One way to reduce the inventory cost without lowering the service level is to have better control over the variability of lead times (Ghaderi and Dullaert, 2012). Also, with rapid development in product globalisation and just-in-time production over the last two decades, customer-oriented freight services are of increasing interest and demand (Hanaoka et al., 2011). Highly responsive networks for fast-moving consumer goods (FMCG) and the automotive industry, for example, illustrate the pressure to better manage inventories by increasing the use of the reliable and faster freight services. Consequently, the time-based attributes of a freight service such as transit-time and reliability have gained momentum as a result of increased attention from academia and industry (Saldanha et al., 2009; van Oort and van Nes, 2010; Berger et al., 2011; Feo et al., 2011; Landex, 2012). Time-based transportation strategies can be relevant and important for freight operators to gain competitive advantage and to provide customer value (Morash and Ozment, 1996). Typically, these strategies are about managing the important sources of customer value that are associated with the time-based attributes of a transportation service.

As a result of changes in the freight distribution requirements, it is clear that the operational scope for rail becomes limited in its ability to compete with the more responsive road transport. The limited playing field for rail is evident in Australia due to 
its disparate population distribution of consumers separated by long distances (Ghaderi et al., 2015a). The Australian freight forwarding industry also broadly delineates freight types according to time-based and cost attributes (BITRE, 2009). Therefore, in this paper the competitiveness of a freight service in Australia is determined from the abovementioned four factors. This approach is pivotal in shaping the theoretical framework of this research.

\section{Theoretical framework}

The non-bulk rail sector is a complex industrial system in terms of operations, policy, regulation and structure (Woodburn, 2008; ARA, 2010). Therefore, the extent to which different elements of the non-bulk rail sector are orchestrated, substantially determines its performance and competitiveness in the freight market (Allen et al., 2010).

The literature on rail competitiveness is scarce and tends to be unsystematically generated. The literature consists of studies that are either explaining rail's declining share in different markets from a service-levels perspective (Shinghal and Fowkes, 2002; Brooks et al., 2012), including the FR (Shinghal, 2005), reliability levels (Kaas, 2000; Vromans et al., 2006), SA and TT (Kanafani et al., 2012); or focusing only on a single element of this complex system. This stream of research for example, focuses on access pricing (Everett, 2005), competition (Behrens and Pels, 2012), infrastructure management (Crozet, 2004), regulations (Cantos and Maudos, 2001; Spychalski and Swan, 2004), policy (Everett, 2006; Dablanc, 2009), funding (Hensher et al., 2012), industry structure (Woxenius and Bärthel, 2002, Williams et al., 2005), environmental impact (Feitelson, 1994) and operational practices (Peng et al., 2013). Due to the dynamic and complex interrelationships between different mechanisms of the rail sector, strategies that aim to improve a particular aspect without examining the consequent impacts on other areas are not necessarily practical (Tsamboulas et al., 2007). For example, a proposed pricing system may increase the FR of a competing transport mode, but can fail to meet the service requirements when interfacing with the rail system.

In addition to the current approach of studying rail competiveness, the operation of non-bulk rail freight is a complex task involving the participation and collaboration of various stakeholders, including above-rail operators, below-rail operators, terminal operators, ports and even the road sector. Therefore, understanding the dynamics of this system requires viewing the rail sector as a system with many organisational ties and actors, including the train operator, track manager, terminal operations and regulator.

This fragmentation in rail competitiveness research has resulted in the shortage of a strong and comprehensive theoretical framework in which different aspects of the rail sector are covered to assess the overall competitiveness of the sector. Therefore, this paper proposes a systems approach for the rail sector in order to identify, evaluate and priorities the key industry challenges and to enable the industry and government to make informed policy, planning and infrastructure decision making. The systems approach developed in this paper is beneficial to investigating the rail sector as a single system while understanding its position in the broader freight market environment.

A systems approach often refers to three key components: inputs, process and output, which this paper applies to the rail sector (Berrien, 1976). According to Jackson (2000), the primary sub-systems of an organisation are mainly: the goal (outcome), tangible resources and technical, human and managerial practices which can be categorised as 
inputs and process respectively. Therefore, inputs can be defined as tangible and intangible assets, whereas both can be translated into assets for a business sector. In a large-scale sector such as rail, assets are numerous due to the multiplicity and interfaces of operations. For example, operations of freight trains are complex with involvement of various supply chain actors and their assets. The assets mainly include below-rail and above-rail infrastructure, intermodal terminals, handling facilities, skilled human resources, financial resources and the required technology to advance.

The second component of the rail system is the process. In a business sector, process can be defined as the practice or know-how of employing the assets to achieve the outcomes (Jackson, 2000). Processes are sometimes developed and implemented by the firms operating in the sector, or as the collective decision of firms under a union or association. Process can also be defined as the policies developed and implemented by the government which controls the market to ensure the economy is free from disorder. In the rail sector, processes mainly include operational practices, regulations, policy, marketing and training. This for example, includes the operational and safety procedures of running freight trains in different parts of the network.

Another major emphasis of this systems approach is on the throughput concept as the processing of production input to yield outcomes that are used by the external environment (Cetin and Cerit, 2010). In other words, the interaction of organisations with their internal resources and the changing external environment requires attention to growth, resource acquisition and external support (Quinn and Rohrbaugh, 1983). This is linked with the third element of systems approach called output. In this sense, the rail sector is a system interacting with other freight actors which uses/utilises resources such as below rail infrastructure and intermodal terminals to provide freight service as the output. In addition, due to the complexity of the rail sector, a systems approach is beneficial to effectively analyse the great number of interactions and actors as a single arrangement and to evaluate its overall competitiveness.

According to the competitiveness concept, the assets and processes are the organisational capabilities to create the outputs (Feurer and Chaharbaghi, 1994). In this sense, the rail sector employs both tangible and intangible assets using the operational practices under certain regulations and policies to create a freight transport service for the customers. Assets and processes are strongly interrelated. The extent to which assets and processes complement each other determines the quality of rail freight services and consequently the competitiveness of the rail sector. Subsequently, feedback from the customers and competing transport modes are systematically linked back to the rail sector for improvement decisions.

The development of the conceptual framework in this paper consists of two stages. First, the systems approach is applied to the competitiveness concept by combining the input and process components of a system to organisational capabilities. The systems approach to competitiveness is then applied to the rail sector.

In the systems approach to competitiveness, rail sector's capabilities aim to create a competitive service in the non-bulk freight market. As shown in Figure 3, assets and processes as the capabilities are in interaction and the feedback from the market is returned the sector for improvement and decision making. This conceptual framework constructs the road map to study the competitiveness of the rail sector by identifying the impediments and evaluating their impacts on the output of the sector and to provide strategies to improve the freight service. 
Considering the objective of this paper, applying a systems approach to the rail sector is beneficial to linking the impeding factors associated with the organisational capabilities of the rail sector and evaluating those factors in relation to the competitiveness of the freight service. The following section presents the empirical approach adopted in this paper.

Figure 3 A systems approach model to enhance rail competitiveness

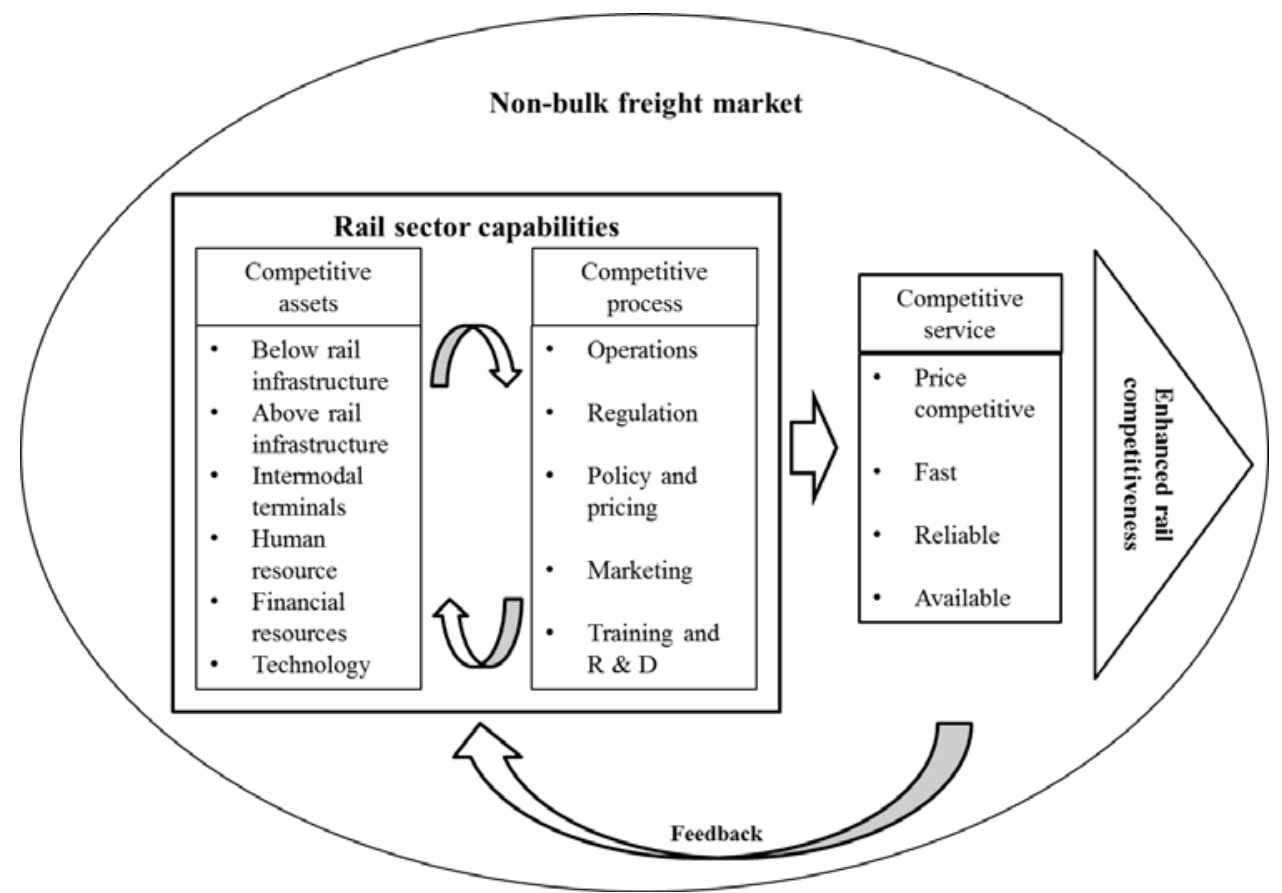

Source: Authors

\section{Methodological approach}

An in-depth survey was designed based on the outcomes of a systematic literature review (SLR) carried out by the authors to identify the factors impeding the competitiveness of the rail sector in Australia (Ghaderi et al., 2015b). The survey included questions evaluating the importance of impeding factors to the different attributes of rail freight service, including FR, TT, reliability (R) and SA. As discussed earlier in Section 2, in this paper the competitiveness of freight service is determined from these factors.

The survey was first pretested with the participation of professionals from both academic and industry sectors to ensure relevance and appropriate terminology for the sample. A stratified sampling strategy was adopted to frame the population under investigation. Stratified sampling is more accurate than simple random sampling, and generates a more representative sample with respect to each stratum (Onwuegbuzie et al., 2010). In addition, by using online survey tools, researchers can observe the response rate in each stratum and reach a greater sample (Gosling et al., 2004; Fricker, 2008). The organisations' contact information was mainly collected from the Australian Rail 
Directory and their websites. Accordingly, the invitation to participate in the online survey was sent to operations and senior managers using e-mail and LinkedIn. LinkedIn was used as a powerful tool to identify, contact and direct the participants to the online survey as personal contact information of participants was not publicly available. Once the participants were identified, data collection was anonymously commenced from 17 August to 17 September 2014. Of the 200 survey questionnaires distributed, 66 completed responses were received, resulting in a response rate of $33.1 \%$.

After the data were collected, exploratory factor analysis (EFA) was conducted for the four FSAs to identify the underlying factors against the quality of individual FSAs. EFA is a powerful statistical tool that explores a factor's structure for a set of observed variables without imposing a predetermined structure on the outcome (Suhr, 2006). In the next stage, mutual factors among all FSAs were identified. This provided the opportunity to identify and priorities the impediments that are most influential on all the FSAs.

\section{Analysis of results}

To evaluate the influence of impediments on the FSAs, the factors derived from the SLR were scaled from 1 being 'not at all influential' to 5 being 'very influential'. All the mean values of the responses are significantly higher than the midpoint of the Likert scale (2.5), revealing that respondents are generally aware of the impeding factors and their impact on different service attributes. Table 1 presents the mean values of respondents' answers with regard to the influence of impediments to different FSAs. Different mean values for each FSA shows that impeding factors have diverse influences on different aspects of service quality.

The descriptive statistics provided in Table 1 shows the impacts of each impediment on different FSAs. This analysis however, presents a general overview and further analysis is required to reduce data to a smaller set of summary variables and to explore the theoretical structure on how FSA are affected. Accordingly, EFA with principal component analysis (PCA) was conducted to bring inter-correlated variables together under general underlying variables. Moreover, as some factors do not have strong applicability to a particular FSA, conducting EFA was important to remove them for the subsequent analysis.

Johnson and Wichern (2014, pp.519-520) explained that the choice of the number of common factors is based on a combination of:

1 the proportion of the sample variance explained

2 subject-matter knowledge

3 the reasonableness of the results. 
Table 1 Influentially degree of impediments to FSA

\begin{tabular}{|c|c|c|c|c|c|}
\hline Code & Impediment & $F R$ & $T T$ & $R$ & $S A$ \\
\hline I. 1 & Inadequate below rail infrastructure & 3.1 & 4.0 & 4.1 & 3.9 \\
\hline I. 2 & Inadequate intermodal terminal infrastructure & 3.0 & 3.5 & 3.7 & 3.8 \\
\hline I. 3 & Shortage of above rail infrastructure & 2.8 & 3.5 & 3.7 & 3.8 \\
\hline I.4 & Rail's inability to provide door-to-door service & 3.1 & 3.2 & 3.1 & 3.2 \\
\hline I.5 & Poor interoperability between player & 3.0 & 3.2 & 3.2 & 3.2 \\
\hline I.6 & Lack of national rail operations standards & 2.5 & 2.7 & 2.9 & 2.7 \\
\hline I.7 & Poor freight distribution systems & 2.9 & 3.2 & 3.2 & 3.2 \\
\hline I. 8 & Different types of pallets and containers & 2.5 & 2.1 & 2.2 & 2.4 \\
\hline I.9 & High terminal charges & 3.5 & 2.2 & 2.3 & 2.4 \\
\hline I. 10 & Inefficient terminal operations & 3.3 & 3.6 & 3.6 & 3.1 \\
\hline I.11 & Diverse management of infrastructure & 2.6 & 3.0 & 2.9 & 3.0 \\
\hline I. 12 & Inconsistent access charging regimes & 3.8 & 2.5 & 2.7 & 2.8 \\
\hline I. 13 & Lack of common vision in government & 3.2 & 3.0 & 3.0 & 3.1 \\
\hline I.14 & Lack of support from government & 3.5 & 3.1 & 3.2 & 3.3 \\
\hline I.15 & Inconsistent public-private partnership policies & 2.8 & 2.5 & 2.5 & 2.7 \\
\hline I. 16 & Uncertainty about capacity for growth & 3.3 & 2.8 & 3.0 & 3.6 \\
\hline I.17 & Diverse demand and growth patterns & 3.2 & 2.9 & 3.0 & 3.3 \\
\hline I.18 & Shortage of reliable data on rail freight & 2.6 & 2.8 & 3.2 & 2.9 \\
\hline I.19 & Poor information sharing and access & 2.8 & 3.0 & 3.1 & 3.3 \\
\hline I. 20 & Shortage of skilled human resource & 3.0 & 3.2 & 3.4 & 3.1 \\
\hline I. 21 & Over-regulation in the rail sector & 3.2 & 3.1 & 3.0 & 3.0 \\
\hline I. 22 & Slow adaption of technology in the rail sector & 3.3 & 3.3 & 3.3 & 3.2 \\
\hline I. 23 & Lack of integrated supply chain thinking & 3.5 & 3.4 & 3.5 & 3.3 \\
\hline I. 24 & Poor performance history of the rail sector & 2.9 & 2.6 & 2.9 & 3.1 \\
\hline I. 25 & Poor customer relationship management & 3.1 & 2.8 & 3.0 & 3.0 \\
\hline I. 26 & Trade unions influence on productivity & 3.1 & 3.2 & 3.3 & 3.1 \\
\hline I. 27 & Adversarial relationship between players & 3.2 & 3.2 & 3.2 & 3.2 \\
\hline \multicolumn{2}{|c|}{ Loadings } & 84.1 & 82.6 & 85.3 & 85.7 \\
\hline \multicolumn{2}{|c|}{ Average } & 3.1 & 3.0 & 3.2 & 3.1 \\
\hline
\end{tabular}

Notes: FR: freight rate, TR: transit time, R: reliability, SA: service availability.

Source: Authors

The reduction of a large number of factors into an adequate number with a clear factor structure is the ultimate aim of factor extraction (Pallant, 2013). Therefore, the Kaiser Criterion is used to determine the number of the principal components. Table 2 details the rescaled rotated component matrix for the four FSAs.

PCA identified four underlying components for each FSA and reduced the number of factors from 27 to 12 for FR, 13 for TT, 14 for reliability and 12 for SA. EFA offered not only the opportunity to gain a clear understanding of the data, but also the possibility to explore the underlying factors for subsequent analysis. In addition, EFA was crucial to identify the factors common among all FSAs. 
Table 2 Rescaled rotated component matrix for four FSAs

\begin{tabular}{|c|c|c|c|c|c|c|c|c|c|}
\hline \multicolumn{10}{|c|}{ Components } \\
\hline & 1 & 2 & 3 & 4 & & 1 & 2 & 3 & 4 \\
\hline \multicolumn{5}{|l|}{$F R$} & \multicolumn{5}{|c|}{$T T$} \\
\hline I. 7 & 0.862 & 0.068 & 0.097 & 0.273 & I. 27 & 0.819 & -0.037 & 0.031 & 0.033 \\
\hline I. 5 & 0.79 & -0.087 & 0.179 & 0.294 & I. 5 & 0.790 & 0.026 & 0.165 & 0.094 \\
\hline I. 8 & 0.777 & 0.221 & 0.037 & -0.159 & I.7 & 0.761 & 0.235 & 0.145 & 0.203 \\
\hline I. 10 & 0.646 & 0.512 & 0.219 & 0.035 & I. 26 & 0.693 & -0.052 & 0.273 & 0.175 \\
\hline I. 12 & 0.043 & 0.766 & 0.213 & 0.299 & I. 10 & 0.559 & 0.383 & 0.321 & -0.43 \\
\hline I. 21 & 0.050 & 0.760 & 0.168 & -0.045 & I.9 & 0.114 & 0.895 & 0 & 0.246 \\
\hline I.9 & 0.215 & 0.688 & 0.246 & 0.144 & I. 15 & 0.098 & 0.796 & 0.088 & -0.002 \\
\hline I. 20 & 0.110 & 0.171 & 0.805 & 0.233 & I. 12 & -0.113 & 0.728 & 0.095 & 0.289 \\
\hline I. 26 & -0.004 & 0.263 & 0.805 & -0.118 & I. 1 & -0.002 & 0.001 & 0.87 & 0.009 \\
\hline I. 27 & 0.277 & 0.204 & 0.742 & -0.016 & I. 2 & 0.278 & 0.126 & 0.784 & 0.042 \\
\hline I. 1 & -0.007 & 0.100 & 0.062 & 0.926 & I. 3 & 0.395 & 0.117 & 0.703 & 0.178 \\
\hline \multirow[t]{2}{*}{ I. 2} & 0.302 & 0.161 & -0.021 & 0.786 & I.6 & 0.161 & 0.276 & 0.103 & 0.809 \\
\hline & & & & & I. 8 & 0.389 & 0.377 & 0.135 & 0.665 \\
\hline$R$ & & & & & \multicolumn{5}{|c|}{$S A$} \\
\hline I. 18 & 0.848 & 0.165 & 0.198 & 0.235 & I. 12 & 0.902 & -0.034 & 0.091 & 0.114 \\
\hline I. 19 & 0.829 & 0.213 & -0.006 & 0.157 & I.9 & 0.783 & -0.205 & 0.294 & -0.096 \\
\hline I. 23 & 0.789 & 0.298 & 0.014 & 0.138 & I. 13 & 0.775 & 0.341 & -0.162 & 0.056 \\
\hline I. 5 & 0.276 & 0.852 & -0.034 & 0.103 & I. 14 & 0.741 & 0.327 & 0.135 & 0.119 \\
\hline I. 10 & 0.096 & 0.711 & 0.055 & 0.354 & I.18 & 0.172 & 0.861 & 0.176 & 0.256 \\
\hline I. 11 & 0.095 & 0.703 & 0.267 & -0.044 & I.19 & -0.024 & 0.804 & 0.223 & 0.194 \\
\hline I. 27 & 0.547 & 0.633 & 0.159 & 0.057 & I. 5 & 0.003 & 0.259 & 0.834 & 0.089 \\
\hline I. 26 & 0.373 & 0.548 & 0.201 & 0.043 & I. 10 & 0.108 & 0.011 & 0.776 & 0.319 \\
\hline I. 12 & -0.055 & 0.143 & 0.893 & 0.115 & I. 27 & 0.169 & 0.575 & 0.642 & 0.031 \\
\hline I. 13 & 0.331 & -0.091 & 0.793 & 0.010 & I. 26 & 0.199 & 0.474 & 0.557 & -0.023 \\
\hline I.9 & -0.223 & 0.280 & 0.755 & -0.041 & I. 1 & -0.019 & 0.146 & 0.053 & 0.878 \\
\hline I. 14 & 0.304 & 0.163 & 0.744 & 0.116 & I. 2 & 0.163 & 0.191 & 0.236 & 0.773 \\
\hline I. 1 & 0.180 & 0.029 & -0.016 & 0.861 & & & & & \\
\hline I. 2 & 0.185 & 0.200 & 0.163 & 0.795 & & & & & \\
\hline
\end{tabular}

Notes: Extraction method: principal component analysis. Rotation method: varimax with Kaiser normalisation. Rotation converged in seven iterations.

Source: Authors' estimation, SPSS 21 output

For each FSA the impeding factors are categorised under their relevant theme. These themes represent the rail industry challenges for improving the freight service quality. The underlying factors related to FR are labelled as:

1 interoperability

2 poor policy and infrastructure charging 
3 human resource and organisational relationship

4 inadequacy of rail infrastructure.

The main factors linked to TT are labelled as:

1 interoperability and organisational relationship

2 poor transport policy and access charging

3 inadequacy of rail infrastructure

4 poor operational standards.

For reliability the main factors are:

1 poor communication and supply chain integration

2 interoperability and organisational relationship

3 poor transport policy

4 inadequacy of rail infrastructure.

Finally, the main factors associated with SA are:

1 poor policy

2 lack of robust communication and integration

3 interoperability and organisational relationship

4 inadequacy of rail infrastructure.

A detailed logistical analysis of themes in relation to service competitiveness is discussed in the following section.

\section{Discussion of results}

This paper investigates the influence of impeding factors faced by the Australian rail industry on various quality aspects of rail freight service. The findings provide important implications for both industry and government in terms of making transport planning and policy decisions. These are discussed in the following sub-sections for each FSA.

\subsection{Freight rate}

Although over the last two decades the demand for a more reliable and flexible freight service has been increasing, the FR is still a key determinant of modal shift in freight markets (Wijeweera et al., 2014). Thus, this FSA is discussed in more depth than those in other sections. According to Australasian Railway Association (ARA), efficient rail should provide a significantly lower cost freight transport system than road on all corridors; for example a $30 \%$ lower cost on the north-south corridor, and $50 \%$ on the east-west corridor (Port Jackson Partners, 2005). However, this has not been achieved to date. It is important to know that these estimates are based on the line-haul component of the freight trip, and not the overall door-to-door intermodal service. Therefore, the pick-up/delivery legs and the terminal handling charges offset the cost advantage of rail 
in the line-haul component Godwin et al., 2013). This problem is also demonstrated by the result of the survey where a key impeding area in relation to cost effectiveness of the rail sector is interoperability. The first component of the EFA includes items I.5, I.7, I.8 and $I .10$ which are all linked to the issue of interoperability. Interoperability refers to the point where freight and information are exchanged between different operators and modes. This component is not linked to the line-haul operations of freight trains, but to the efficiency of interaction between rail and road in the intermodal terminals and a lack of control over the distribution system when the pick-up/delivery tasks are undertaken. In addition to the terminal operation, participants demonstrated that different sizes of pallets and containers potentially add extra cost to the FR. This is particularly true as different sizes of handling units require additional equipment, excessive handling operations and results in poor utilisation of space.

The second component in the EFA is directly linked with the cost-related impediments, including high terminal charges (I.9), inconsistent infrastructure access charging between road and rail (I.12) and over-regulation in the rail sector (I.21). Terminal handling charges are one of the highest cost components of an overall intermodal journey (Shipping Australia, 2011). The Australian Competition and Consumer Commission (ACCC) has expressed important concerns about terminal handling charges and competition structure which can significantly impact the overall efficiency of the intermodal chains. ACCC has an explicit focus on the charging strategies across the seaports in which there may be conditions where an operator is able to use its position to unfairly hold back a new entrant from establishing itself at that port and/or at other ports (ACCC, 2013). This will consequently abolish productivity in the markets where competition is limited. Inconsistent access charging is also a key concern for the rail sector. Due to long distances between the main population centres, freight trains operate within a very limited passenger market to share the fixed infrastructure cost, whereas nearly $90 \%$ of traffic on interstate road corridors (where rail and road compete for freight volumes) is comprised of light vehicles (ARTC, 2006; Ghaderi et al., 2015a, 2016). Another key issue for the rail sector which was identified in the survey was over-regulation, mainly due to the excessive cost that it imposes to operations. The adverse impact of multiple regulatory systems (safety and access) has an adverse impact by increasing the bureaucratic and administrative costs as the objectives set by one regulator may not be in alignment with objectives set by another (BTRE, 2006a).

The shortage of skilled human resources (I.20), influence of trade unions on productivity (I.26) and adversarial relationship between freight players (I.27) also influence freight cost. The National Transport Commission (NTC) has raised two important concerns in relation to training and skills development which potentially determine the cost efficiency and subsequent FR s offered by the rail sector. Firstly, it was emphasised that the current rail sector workforce has very little understanding of how intermodal chains operate (NTC, 2004). As a consequence, it is suggested that productivity improvement initiatives will not be effective until this understanding is achieved. Lastly, the shortage of below-rail (I.1) and intermodal (I.2) infrastructure revealed the necessity for developing a nationally significant infrastructure for the rail freight sector that is cost effective. This issue is particularly essential in the metropolitan and port areas in which the freight trains share the infrastructure with the highly prioritised passenger trains. 


\subsection{TT and reliability}

Long TT and poor reliability levels offered by the rail sector are a key concern of freight customers in Australia, hindering their use of rail for many freight movements (Ernst \& Young, 2006). The estimates from the Bureau of Infrastructure, Transport and Regional Economics (BITRE) suggest that the average door-to-door TTs offered by road are $20 \%$ less than those of line-haul rail. This means once the pick-up/delivery and terminal operations times are added, the differential door-to-door TTs between road and rail is much greater (BITRE, 2009). Additionally, reliability levels of rail have remained around 40 to $50 \%$ on the key interstate corridors, while road's reliability has been around 95 to 98\% (BITRE, 2009). The focus of respondents' answers to this area is very similar to those of the FR, including factors linked with interoperability, terminal operations and shortage of infrastructure (I.1, I.2, I.3, I.5, I.7, I.8, I.10, I.26 and I.27). Respondents also indicated that poor information sharing (I.18) and shortage of reliable data on freight were of concern (I.19).

Rail operations have little control over the TT of the overall freight journey. Therefore, efficient and effective integration between the different parties involved in undertaking the intermodal freight service determines the total time that freight requires reaching the customer's destination. Although enhancing track or terminal productivity or implementing new operational practices are essential to improve service quality, a higher level of collaboration and coordination is required across the entire intermodal chain (as demonstrated by I.23). Rail actors must understand how the timeliness and punctuality of their task influences the performance of up-stream tasks, and consequently the quality of time-based attributes of the freight service.

\subsection{Service availability}

SA for an intermodal rail service is defined as the number of weekly trains operating between two given points or the line segment of the network. Unlike road transport, the mobility of freight trains is naturally limited by the extent to which the below-rail infrastructure is developed. Therefore, decision making on SA is a complex process and involves various factors, including locomotive availability, rolling stock availability, track usage and the accessibility of intermodal infrastructure to the freight markets. Reflecting the substantial gauge differences that exist across the Australian railway network, train operators face further challenges as different gauge sizes require distinct above-rail infrastructure (locomotive and rolling stock). This does not only impose excessive costs to the train operator, but also significantly restricts the mobility of the above-rail infrastructure across the network. The survey results indicate that inadequate below-rail (I.1) and intermodal infrastructure (I.2) are key impediments to SA. This is particularly true in the case of Australia as the railways and intermodal system have not penetrated into regional areas. In contrast, the road network is soundly developed, meaning that road has a major advantage over rail in terms of SA in regional areas. In addition to infrastructure shortage, the SA of rail has a correlation with cost factors, including access charging prices (I.12), terminal charges (I.9) and lack of support and common vision to support rail from different levels of government (I.13 and I.14). Railway systems have strong economies of scale through density in above-rail and below-rail operations, meaning that incremental traffic volumes will have significant impact on reducing the carrying unit operational cost (BTRE, 2006b). Most of the 
Australian railway network is under-utilised and operated under low traffic volumes, implying low financial returns (BTRE, 2006a), and indicating that with the current state of infrastructure rail cannot be commercially viable in many areas of the market. However, this is not an issue in urban areas, especially those parts of the network linked to ports where rail corridors are too short to ensure economies of scale (Ghaderi et al., 2015c). Therefore, improving rail's SA is a complex issue for both the government and the rail sector, requiring significant investment in infrastructure or heavy subsidisation of FRs.

To conclude this section, it was demonstrated in Table 2 that eight impediments are communal among the four FSAs, including I.1, I.2, I.5, I.9, I.10, I.12, I.26 and I.27. These impediments are categorised as infrastructure management and operations (I.1, I.2 and I.10), interoperability (I.5), infrastructure access charging (I.5 and I.1) and organisational and commercial relationships (I.26 and I.27). Conducting EFA for all FSAs was found to be useful to:

1 reduce the number of factors to those that are most important from the rail sector perspective

2 identify the unique impediments associated with each FSA

3 to understand what challenges are common among all FSAs.

Figure 4 demonstrates the summary of data analysis and synthesis.

Figure 4 Summary of data analysis and synthesis

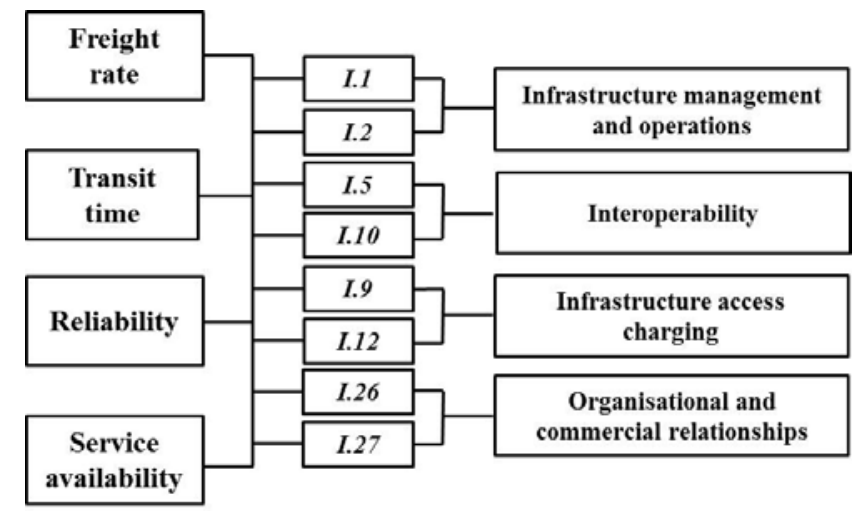

Source: Authors

\section{Findings, recommendations and direction for future research}

The previous sections provided important implications related to the factors affecting the competitiveness of the Australian rail sector. The main objective of this paper was to identify the key factors influencing the quality of different FSAs, and consequently the overall competitiveness of the rail sector. The result of EFA identified factors that are explicit to a particular FSA, but also those which are common. This is an important 
achievement as it assists the rail industry and government to target the poor FSAs and the associated impediments. The analysis shows that three key areas of challenge exist relating to:

1 infrastructure management

2 interoperability

3 organisational and commercial relationships.

The findings of this paper have the following managerial implications and recommendations for improving the current rail service.

First, non-bulk freight is becoming an increasingly important part of the rail freight sector in Australia. This task is projected to grow much faster than the rate of population growth and the average national GDP growth. To cater for the projected demand, further development of rail infrastructure is required, including standardisation of available gauges, opening of new freight corridors in the urban areas (especially ports) and establishment of new intermodal terminals. Particularly in the low-populated areas, small and medium-sized terminals are key facilitators for attracting cargo for rail.

Second, poor interoperability between different operators and modes is a key issue to the competitiveness of the rail sector in Australia. A lack of integration in terms of the physical movement of freight and information is where inefficiencies arise. For example, lack of integration may result in duplication of activities within the exchange points, excessive dwell times, congestion and additional equipment. The findings rising from this paper suggest greater standardisation is required to enhance integration and interoperability. Standardisation is delineated in various ways, including harmonisation in the transaction of information, standardisation of unit loads and elimination of unnecessary inspections.

Third, an adversarial relationship and culture appears to exist across the non-bulk freight industry. In addition, the rail sector has failed to manage its organisational ties across the system. This failure is not only limited to the relationships between the rail sector and other key actors (including road, ports and terminal operators), but also it is a severe issue between the different parties involved in the operation of freight trains, especially between above-rail and below-rail operators. Reflecting the operational complexity of intermodal rail freight in size and interaction, greater collaboration is required to achieve productivity in the rail sector.

The implications derived from this study indicate that the FR is still a key area for rail to achieve competitive advantage. Taking into account the natural characteristics of rail transport, it is challenging for rail to easily provide better levels of TT (especially on short corridors), reliability and SA. Therefore, the recommendations provided in this section must take this key point into the decision making process.

This paper makes several contributions to the industry and academia. Firstly, it provides a more transparent image of the key challenges faced by the rail sector in Australia. These challenges were ambiguous previously, mainly due to lack of empirical research and absence of stakeholder involvement. This research therefore, provides a detailed understanding of these challenges in a national context. Secondly, this paper also contributes to the disciplines of competitiveness and systems management by developing a conceptual framework which integrates the systems approach into the competitiveness concept. This approach is beneficial to evaluate the competitiveness of an industrial 
sector by identifying its particular components (inputs, processes and outputs) and investigate how these components influence the competitiveness.

This research provides several directions for future research. Firstly, this paper investigated the view of rail freight sector on the key challenges on various service quality attributes. As a future research, the importance of different service attributes from the shippers and freight forwarders perspectives can be studied to be integrated with the outcomes of this thesis. This in consequence, will provide valuable information for the rail sector to target the poor attributes which demand higher service levels from the freight customers. Further investigation is required on understanding the poor FSAs in different sub-markets (including interstate, intrastate and port-based) and investigating the associated unique impediments. This would allow the freight operators and government to identify the poor FSAs in different sub-markets and make relevant infrastructure and planning decision making.

\section{References}

ACCC (2013) Container Stevedoring Monitoring Report No. 15, Australian Competition and Consumer Commission, Canberra, ACT.

Allen, J., Browne, M. and Woodburn, A.G. (2010) 'Integrated transport policy in freight transport', in Givoni, M. and Benister, D. (Eds.): Integrated Transport: From Policy to Practice, Routledge, Hoboken, NJ.

ARA (2010) Submission to Infrastructure Australia's National Freight Network Plan, Australasian Railway Association, Barton, ACT.

Arencibia, A.I., Feo-Valero, M., García-Menéndez, L. and Román, C. (2015) 'Modelling mode choice for freight transport using advanced choice experiments', Transportation Research Part A: Policy and Practice, Vol. 75, No. 1, pp.252-267.

ARTC (2006) Productivity Commission Inquiry into Road and Rail Freight Infrastructure Pricing, Australian Rail Track Corporation Adelaide, SA.

ARTC (2015) Inland Rail, Australian Rail Track Corporation, Adelaide, SA.

Behrens, C. and Pels, E. (2012) 'Intermodal competition in the London-Paris passenger market: high-speed rail and air transport', Journal of Urban Economics, Vol. 71, No. 3, pp.278-288.

Bergantino, A.S., Bierlaire, M., Catalano, M., Migliore, M. and Amoroso, S. (2013) 'Taste heterogeneity and latent preferences in the choice behaviour of freight transport operators', Transport Policy, Vol. 30, No. 1, pp.77-91.

Berger, A., Hoffmann, R., Lorenz, U. and Stiller, S. (2011) 'Online railway delay management: hardness, simulation and computation’, Simulation, Vol. 87, No. 7, pp.616-629.

Berrien, F.K. (1976) 'A general systems approach to organizations', in Dunnette, M.D. and Hough, L.M. (Eds.) Handbook of Industrial and Organizational Psychology, Rand McNally College Publishing, Chicago, IL.

BITRE (2009) Road and Rail Freight: Competitors or Complements?, Bureau of Infrastructure, Transport and Regional Economics, Canberra, ACT.

BITRE (2012) Trainline1, Bureau of Infrastructure, Transport and Regional Economics, Canberra, ACT.

BITRE (2014a) Australian Infrastructure Statistics Yearbook 2014, Bureau of Infrastructure, Transport and Regional Economics, Canberra, ACT.

BITRE (2014b) Freightline1, Bureau of Infrastructure, Transport and Regional Economics, Canberra, ACT.

BITRE (2014c) Trainline2, Bureau of Infrastructure, Transport and Regional Economics, Canberra, ACT. 
Booz \& Co (2008) Capacity Constraints \& Supply Chain Performance - Intermodal 1, National Transport Commission, Melbourne, VIC.

Brooks, M.R., Puckett, S.M., Hensher, D.A. and Sammons, A. (2012) 'Understanding mode choice decisions: a study of Australian freight shippers', Maritime Economics \& Logistics, Vol. 14, No. 3, pp.274-299.

BTRE (2006a) Optimizing Harmonisation in the Australian Railway Industry, Bureau of Transport and Regional Economics, Canberra, ACT.

BTRE (2006b) Submission to the Productivity Commission Road and Rail Freight Infrastructure Pricing Inquiry, Bureau of Transport and Regional Economics, Canberra, ACT.

Cantos, P. and Maudos, J. (2001) 'Regulation and efficiency: the case of European railways', Transportation Research Part A: Policy and Practice, Vol. 35, No. 5, pp.459-472.

Cetin, C.K. and Cerit, A.G. (2010) 'Organizational change and effectiveness in seaports from a system viewpoint', in Grammenos, C.T.H. (Ed.): The Handbook of Maritime Economics and Business, Lloyd's List, London, UK.

Crozet, Y. (2004) 'European railway infrastructure: towards a convergence of infrastructure charging?', International Journal of Transport Management, Vol. 2, No. 1, pp.5-15.

Dablanc, L. (2009) 'Regional policy issues for rail freight services', Transport Policy, Vol. 16, No. 4, pp.163-172.

Danielis, R., Marcucci, E. and Rotaris, L. (2005) 'Logistics managers' stated preferences for freight service attributes', Transportation Research Part E: Logistics and Transportation Review, Vol. 41, No. 3, pp.201-215.

Edwards, P., Peters, M. and Sharman, G. (2001) 'The effectiveness of information systems in supporting the extended supply chain', Journal of Business Logistics, Vol. 22, No. 1, pp.1-27.

Ernst \& Young (2006) North-South Rail Corridor Study, Sydney, NSW.

Everett, S. (2005) 'Jurisdictional and constraints on effective competition: the case of rail access regimes', Australian Journal of Public Administration, Vol. 64, No. 4, pp.90-98.

Everett, S. (2006) 'Deregulation and reform of rail in Australia: some emerging constraints', Transport Policy, Vol. 13, No. 1, pp.74-84.

Fahimnia, B., Reisi, M., Paksoy, T. and Özceylan, E. (2013) 'The implications of carbon pricing in Australia: an industrial logistics planning case study', Transportation Research Part D: Transport and Environment, Vol. 18, No. 1, pp.78-85.

Feitelson, E. (1994) 'The potential of rail as an environmental solution: setting the agenda', Transportation Research Part A: Policy and Practice, Vol. 28, No. 3, pp.209-221.

Feo, M., Espino, R. and García, L. (2011) 'An stated preference analysis of Spanish freight forwarders modal choice on the south-west Europe Motorway of the Sea', Transport Policy, Vol. 18, No. 1, pp.60-67.

Feurer, R. and Chaharbaghi, K. (1994) 'Defining competitiveness: a holistic approach', Management Decision, Vol. 32, No. 2, pp.49-58.

Flodén, J., Bärthel, F. and Sorkina, E. (2010) 'Factors influencing transport buyer's choice of transport service - a European literature review', The 12th WCTR Proceedings, Lisbon, Portugal.

Fowkes, A.S., Firmin, P.E., Tweddle, G. and Whiteing, A.E. (2004) 'How highly does the freight transport industry value journey time reliability - and for what reasons?', International Journal of Logistics: Research and Applications, Vol. 7, No. 1, pp.33-43.

Fricker, R.D. (2008) 'Sampling methods for web and e-mail surveys', in Fielding, N., Lee, R. and Blank, G. (Eds.) Handbook of Online Research Methods, Sage, Thousand Oaks, CA.

Ghaderi, H. and Dullaert, W. (2012) 'An empirical investigation of lead-time reduction in purchasing groups: evidence from SMEs', International Journal of Logistics Systems and Management, Vol. 13, No. 3, pp.379-392.

Ghaderi, H., Cahoon, S. and Nguyen, H-O. (2015a) 'An investigation into the non-bulk rail freight transport in Australia', The Asian Journal of Shipping and Logistics, Vol. 31, No. 1, pp.59-83. 
Ghaderi, H., Fei, J. and Cahoon, S. (2015b) 'The impediments to the competitiveness of the rail industry in Australia: the case of the non-bulk freight market', Asia Pacific Journal of Marketing and Logistics, Vol. 27, No. 1, pp.127-145.

Ghaderi, H., Cahoon, S. and Nguyen, H-O. (2015c) 'Impediments to the competitiveness of rails ector in the Australian port-based container market', Proceedings of the International Association of Maritime Economists Conference, Kuala Lumpur, Malaysia.

Ghaderi, H., Cahoon, S. and Nguyen, H-O. (2016) 'The role of rail in the Australian port-based container market: challenges and opportunities', Australian Journal of Maritime and Ocean Affairs, Vol. 8, No. 1, pp.1-20.

Godwin, T., Gopalan, R. and Narendran, T. T. (2013) 'Factors influencing the design of a linear network for a dedicated freight corridor', International Journal of Logistics Systems and Management, Vol. 14, No. 1, pp.73-92.

Gosling, S.D., Vazire, S., Srivastava, S. and John, O.P. (2004) 'Should we trust web-based studies? A comparative analysis of six preconceptions about internet questionnaires', American Psychologist, Vol. 59, No. 2, pp.93-104.

Grosso, M. (2011) 'Variables influencing transport mode choice: a generalized costs approach', Società Italiana di Economiadei Trasporti e della Logistica - XIII Riunione Scientifica, Messina, Italy.

Hanaoka, S., Husnain, T., Kawasaki, T. and Kunadhamraks, P. (2011) 'Measurement of energysaving effect by intermodal freight transport in Thailand', World Review of Intermodal Transportation Research, Vol. 3, No. 4, pp.320-337.

Hensher, D.A., Truong, T.P., Mulley, C. and Ellison, R. (2012) 'Assessing the wider economy impacts of transport infrastructure investment with an illustrative application to the North-West Rail Link project in Sydney, Australia', Journal of Transport Geography, Vol. 24, pp.292-305.

Jackson, M.C. (2000) Systems Approaches to Management, Springer Science \& Business Media, Berlin, Heidelberg.

Johnson, R.A. and Wichern, D.W. (2014) Applied Multivariate Statistical Analysis, Pearson Education Limited, New York, NY.

Kaas, A. (2000) 'Punctuality model for railways', Proceedings of the International Conference on Computers in Railways, Bologne, Italy.

Kanafani, A., Wang, R. and Griffin, A. (2012) 'The economics of speed - assessing the performance of high speed rail in intermodal transportation', Procedia - Social and Behavioral Sciences, Vol. 43, No. 1, pp.692-708.

Kuo, A. and Miller-Hooks, E. (2012) 'Developing responsive rail services through collaboration', Transportation Research Part B: Methodological, Vol. 46, No. 3, pp.424-439.

Landex, A. (2012) 'Reliability of railway operation', Proceedings of the Annual Transport Conference, Aalborg, Denmark.

Lu, C.S. (2003) 'The impact of carrier service attributes on shipper-carrier partnering relationships: a shipper's perspective', Transportation Research Part E: Logistics and Transportation Review, Vol. 39, No. 5, pp.399-415.

Mehbub Anwar, A.H.M., Tieu, K., Gibson, P., Win, K.T. and Berryman, M.J. (2014) 'Analyzing the heterogeneity of traveler mode choice performance using a random parameter logit model from the perspective of principle-agent theory', International Journal of Logistics Systems and Management, Vol. 17, No. 4, pp.447-471.

Meixell, M.J. and Norbis, M. (2008) 'A review of the transportation mode choice and carrier selection literature', The International Journal of Logistics Management, Vol. 19, No. 2, pp.183-211.

Meng, S., Siriwardana, M. and McNeill, J. (2013) 'The environmental and economic impact of the carbon tax in Australia', Environmental and Resource Economics, Vol. 54, No. 3, pp.313-332.

Monczka, R., Handfield, R., Giunipero, L. and Patterson, J. (2008) Purchasing and Supply Chain Management, Cengage Learning, Boston, MA. 
Morash, E.A. and Ozment, J. (1996) 'The strategic use of transportation time and reliability for competitive advantage', Transportation Journal, Vol. 36, No. 2, pp.35-46.

Murphy, P.R. and Poist, R.F. (2000) 'Third-party logistics: some user versus provider perspectives', Journal of Business Logistics, Vol. 21, No. 1, pp.121-133.

NTC (2004) Impediments to Improving Efficiency in the Area of Intermodal Transport, National Transport Commission, Melbourne, VIC.

OECD (2010) Improving Reliability on Surface Transport Networks, International Transport Forum, Paris, France.

Onwuegbuzie, A.J., Bustamante, R.M. and Nelson, J.A. (2010) 'Mixed research as a tool for developing quantitative instruments', Journal of Mixed Methods Research, Vol. 4, No. 1, pp.56-78.

Pallant, J. (2013) SPSS Survival Manual, Allen \& Unwin, Crows Nest, NSW.

Peng, Q., Zhao, J. and Wen, C. (2013) 'A rolling horizon-based decomposition algorithm for the railway network train timetabling problem', International Journal of Rail Transportation, Vol. 1, No. 3, pp.129-160.

Port Jackson Partners (2005) The Future of Freight, Australasian Railway Association, Barton, ACT.

Quinn, R.E. and Rohrbaugh, J. (1983) 'A spatial model of effectiveness criteria: towards a competing values approach to organizational analysis', Management Science, Vol. 29, No. 3, pp.363-377.

Reis, V. (2014) 'Analysis of mode choice variables in short-distance intermodal freight transport using an agent-based mode', Transportation Research part E: Policy and Practice, Vol. 61, pp. $100-120$.

Saldanha, J.P., Tyworth, J.E., Swan, P.F. and Russell, D.M. (2009) 'Cutting logistics costs with ocean carrier selection', Journal of Business Logistics, Vol. 30, No. 2, pp.175-195.

Santos, B.F., Limbourg, S. and Carreira, J.S. (2015) 'The impacts of transport policies on railroad intermodal freight competitiveness - the case of Belgium', Transportation Research Part D: Transport and Environment, Vol. 34, pp.230-244.

Saranen, J. and Hilmola, O-P. (2007) 'Evaluating the competitiveness of railways in timber transports with discrete-event simulation', World Review of Intermodal Transportation Research, Vol. 1, No. 4, pp.448-458.

Shinghal, N. (2005) 'Rail-road competition in freight transportation: price and service issues', Economic and Political Weekly, Vol. 40, No. 25, pp.2587-2593.

Shinghal, N. and Fowkes, T. (2002) 'Freight mode choice and adaptive stated preferences', Transportation Research Part E: Logistics and Transportation Review, Vol. 38, No. 5, pp.367-378.

Shipping Australia (2011) Metropolitan Intermodal Terminal Study, Shipping Australia Limited, Sydney, NSW.

Spychalski, J.C. and Swan, P.F. (2004) 'US rail freight performance under downsized regulation', Utilities Policy, Vol. 12, No. 3, pp.165-179.

Suhr, D.D. (2006) Exploratory or Confirmatory Factor Analysis?, Paper 200-31, University of Northern Colorado, Greeley, CO.

Tsamboulas, D., Vrenken, H. and Lekka, A-M. (2007) 'Assessment of a transport policy potential for intermodal mode shift on a European scale', Transportation Research Part A: Policy and Practice, Vol. 41, No. 8, pp.715-733.

van Oort, N. and van Nes, R. (2010) 'Impact of rail terminal design on transit service reliability', Transportation Research Record: Journal of the Transportation Research Board, Vol. 2146, No. 1, pp.109-118.

Vromans, M.J., Dekker, R. and Kroon, L.G. (2006) 'Reliability and heterogeneity of railway services', European Journal of Operational Research, Vol. 172, No. 2, pp.647-665. 